\title{
Influence of the new construction to settlement of historical building when accounting hardening of medium sand in basement
}

\author{
Dmitriy Chunyuk * and Daria Rasskazova \\ Moscow State University of Civil Engineering, Yaroslavskoe shosse, 26, Moscow, 129337, Russia
}

\begin{abstract}
Currently, a number of difficulties arise in the construction of dense urban areas, as well as in the reconstruction and superstructure of existing buildings and structures. Often when carrying out geological scene investigation, it is not possible to determine the strength parameters of the soil directly under the foundation. In most cases, this leads to understating of its characteristics, which is reflecting in the excessive economic costs resulting from the need to strengthen the existing building structure. However, in many situations, this can be discarded, justifying it by calculations. In this paper is shows the performed series of numerical experiments and were analyzed the changes of existing building foundation settlements, taking into account its long-term exploitation in assessing the impact of new construction. The base had defined by a single-layer halfspace with a limited depth of deformation zone and composed of mediumsized sand. PLAXIS 2D software was chosen to create the calculation model. When processing the results, it was possible to identify a certain dependence that allows estimating the maximum settlement of existing building in the impact assessing from new construction taking into account the duration of building operation. The obtained data prove the necessity to take into account the change in strength properties of soils caused by longterm loads action of structures.
\end{abstract}

\section{Introduction}

At present, special attention is paid to calculations in assessing the impact of new construction on the surrounding buildings.

On the issue of duration exploitation effect at buildings to the properties of the foundation soils, a large number of experimental and theoretical studies have been carried out [1-8]. They showed that over time a change in the physical and mechanical properties of basement soil, which is due influencing of various factors.

First of all, this is a long-term effect of loads on the base during operation, causing soil compaction. Because of compaction, its physical, strength and deformation properties are improved. These soil properties transformations at basement of long-term exploitation buildings foundations are amenable to forecasting and can be taken into account calculations.

\footnotetext{
* Corresponding author: chunyuk@mail.ru
} 
The many buildings of long-term exploited are historical and architectural monuments, for which very strict requirements are imposed for deformation of basement. For example, according to Russian national code SP 22.13330.2011 "Soil bases of buildings and structures", the limiting additional deformations for basement of multi-floor and singlefloor historic buildings or historical, architectural and cultural monuments with brickwork main walls without reinforcement are limited as follows: the relative difference in precipitation should not exceed $4 \times 10^{-4}$, and the maximum draft is $5 \mathrm{~mm}$.

The purpose of this work is analysis of building foundation settlements, taking into account the changes strength properties of basement soils during long-term exploitation in assessing the impact of new construction.

\section{Methods}

In the paper of Yu. Dvorkin [1], linear relationships between the strength characteristics of sandy soils and their duration of loading were proposed. Using following empirical formulas for determining the angle of internal friction and intercept cohesion for mediumsized sands, calculations were made in predicted time point for to estimate influence of construction on existing building with a service life of 100 years:

$$
\begin{aligned}
& \varphi_{-}=\varphi_{-} 0+0.0614 \mathrm{t} \\
& c_{-} \mathrm{t}=\mathrm{c}_{-} 0+0.000372 \mathrm{t}
\end{aligned}
$$

One of most reliable ways for forecasting the change in the stress-strain state of basement, allowing to take into account the largest number of factors affecting its results (mechanical properties of the soil, geometric and rigid parameters of the foundations, complex interaction of the basement with a foundation, etc.) is mathematical modeling by finite element method with help of special geotechnical software systems.

To create a geomechanical model (figure 1), the PLAXIS 2D software was chosen.

The following prerequisites were used when performing mathematical modeling.

The base is defined by a single-layer half-space with a limited depth of compressible thickness and is composed of medium-sized sand. The Hardening Soil model determined the behavior of soil.

The Hardening Soil model is an improved model of Mohr-Coulomb, designed to simulate the behavior of various soils, taking into account the change in their deformation parameters according to hyperbolic dependence $\sigma_{1}-\sigma_{3}-\varepsilon_{1}$. The reasons for choosing this model as the main one is, first of all, the presence in the soil parameters of not one, but several deformation characteristics, which allow calculating soil behavior not only during loading but also during unloading, which is observed when excavating soil from the excavation. Such an approach, with precise assignment of parameters, allows obtaining more reliable values of soil deformations in comparison with the results of calculations based on the Mohr-Coulomb model.

Using the Buckingham $\pi$ theorem, have been determining members of function relationship dependence settlement of existing building foundation on factors of calculation model in a dimensionless form were determined, which helped determine the main factors for conducting numerical experiments by DOE method.

Flat calculated sections pass through the building under construction with a depth of excavation $\mathrm{H}$ equal $6 \mathrm{~m}, 9 \mathrm{~m}$ and $12 \mathrm{~m}$ and number of strut floor $\mathrm{n}$ equal to 1,2 and 3 , respectively. The distance between a diaphragm wall and the existing building $\mathrm{L}$ equal $2 \mathrm{~m}$, $5 \mathrm{~m}, 10 \mathrm{~m}$ and $15 \mathrm{~m}$.

The building under construction is a monolithic building with a full frame. The excavation is planned to be carried out using the diaphragm wall, which is made using the 
"wall in the ground" technology from reinforced concrete. A structure of foundation is adopted in the form of reinforced concrete plate.
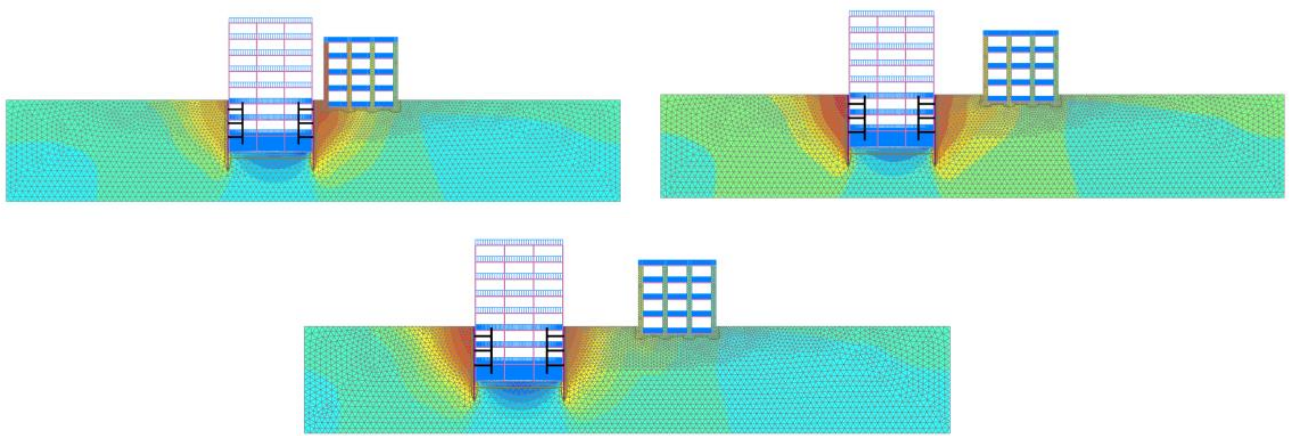

Fig. 1. Examples of used calculation schemes

As noted above, in the basements of long-term exploited buildings, the increase in the strength characteristics of soils or the so-called "hardening effect" is due to their compaction. Therefore, it was decided to analyze the soil compaction zone (figure 2a).

The initial coefficient of soil porosity was 0.650. Figure $2 \mathrm{a}$ shows isopoles of the porosity coefficient from 0.640 to 0.647 after a long operation of the building, which correspond to soil compaction by $0.5 \ldots 1.5 \%$, respectively. This area was taken as the hardening zone of the base and approximated to perform calculations taking into account this effect as shown in figure $2 b$.

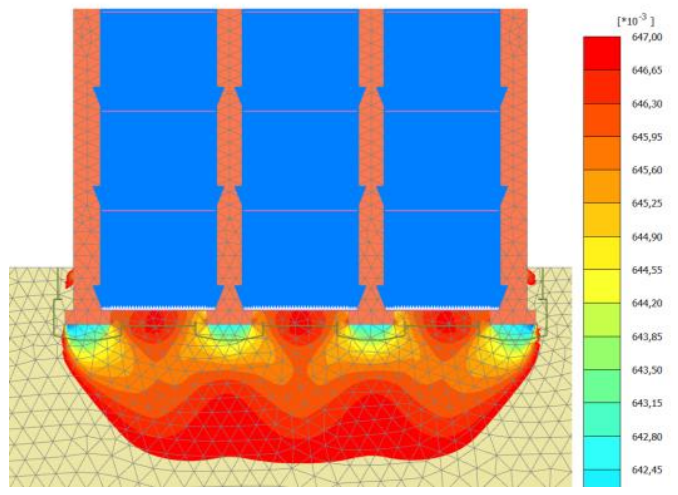

a)

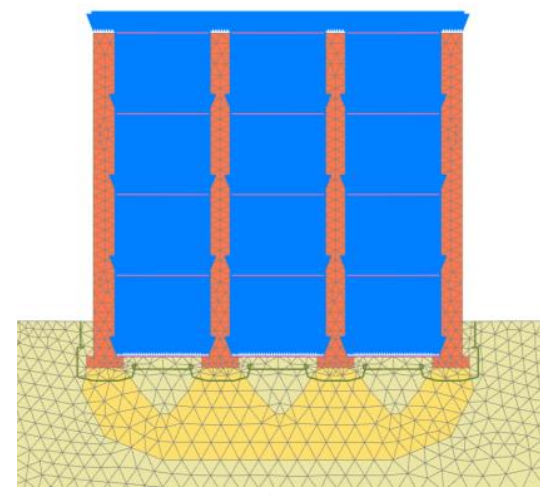

b)

Fig. 2. Basement hardening zone ( $\mathrm{a}-$ according to calculation data, $\mathrm{b}$ - accepted approximation)

\section{Results}

In this paper, 24 calculations cases of simulation of excavation structures in relation to the existing building were considered. For each calculation case, the foundation settlements were determined without taking into account the duration of the loads and at the time $t$ equel 100 years. The numbers of foundations in the calculated cases increase with the distance from the workings. The results of the assessment of the change in these parameters are shown in figure 3. 


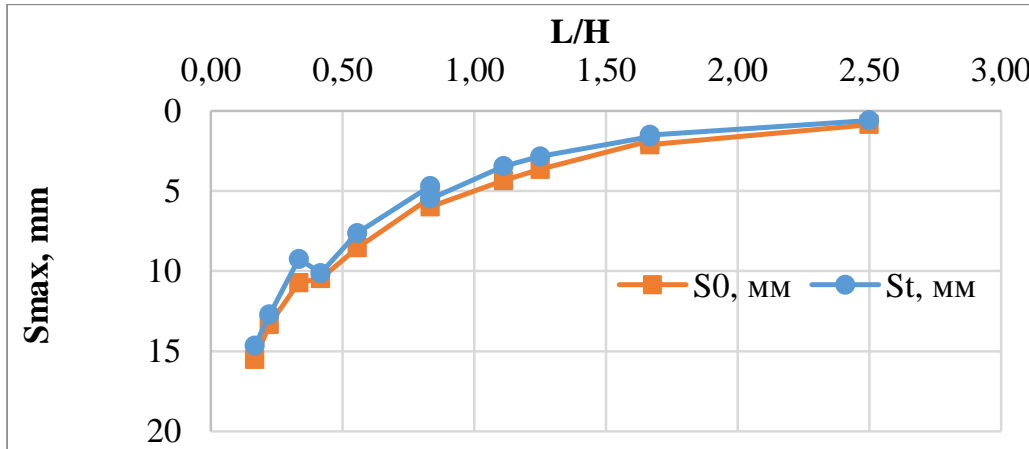

a)

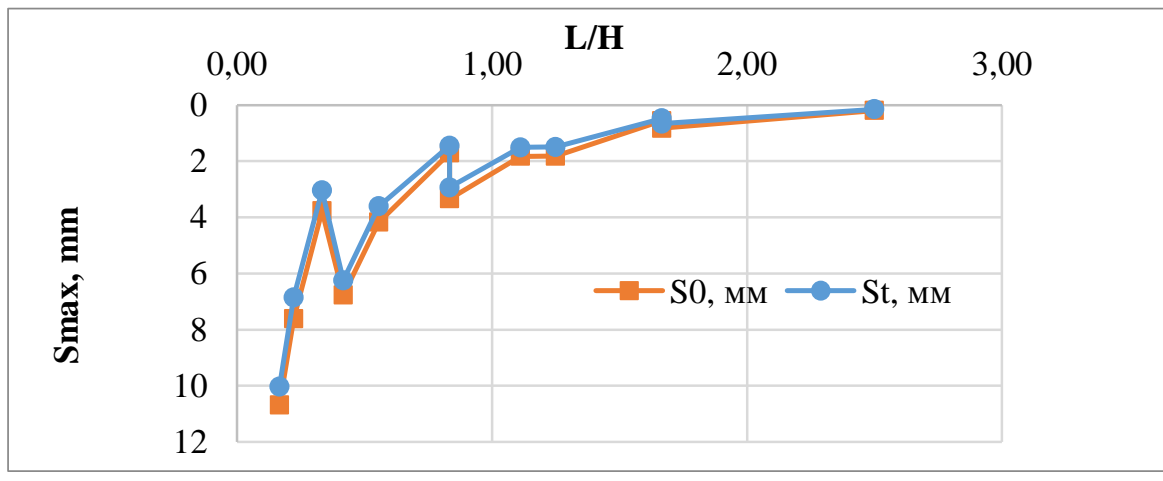

b)

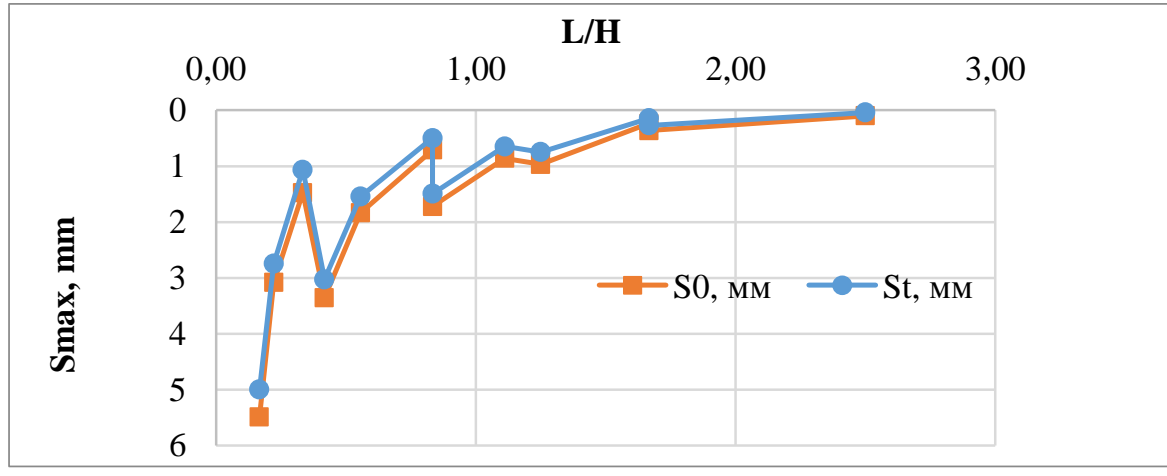

c)

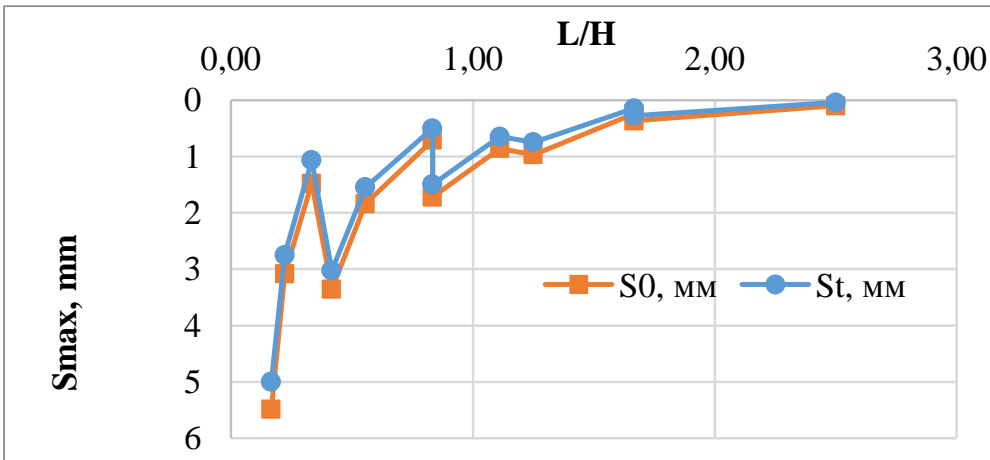

d)

Fig. 3. Graphs of maximum settlements of foundations from the relation $\mathrm{L} / \mathrm{H}$ without taking into account the duration of loads and for a time $t$ equal 100 years ( $a$ - foundation No.1, $b$ - foundation No.2, c - foundation No.3, d - foundation No.4) 
Dependence of the maximum settlement, taking into account the exploited time $S_{t}$ from the maximum settlement $S_{0}$ determined by the traditional method, is given by the function of the form $S_{-} t=f\left(S_{0}, H, L, h\right)$. The form of the function and its members are defined by the graph shown in figure 4.

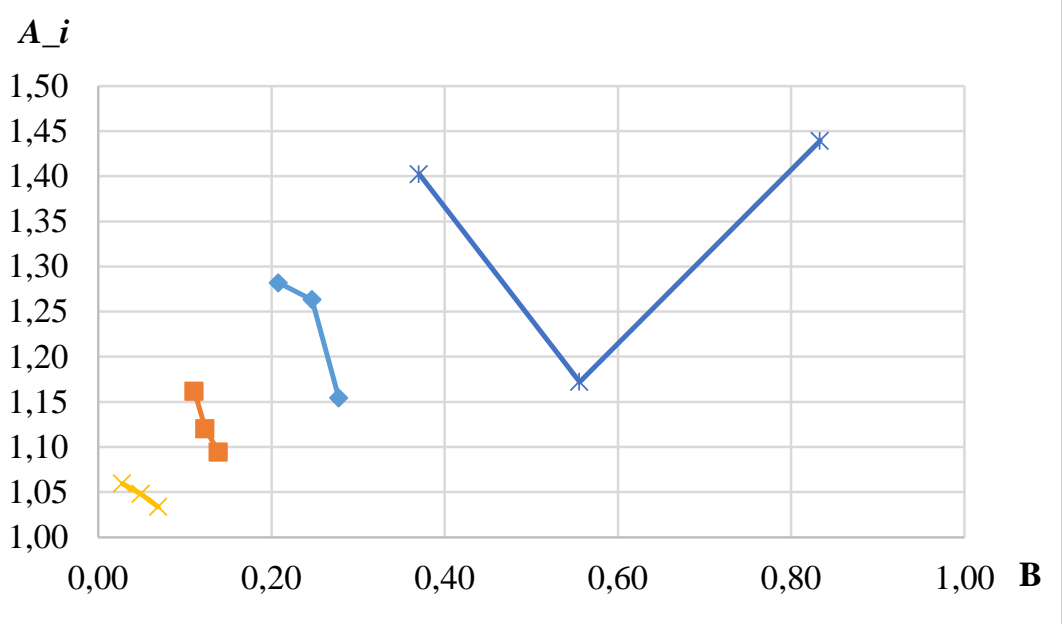

Fig. 4. Dependency graph $A \_i$ from $B$

$$
S_{-} t=\left\{\begin{array}{l}
\frac{1}{A_{1}} S_{0} ; 0.03 \leq B \leq 0.07, \\
\frac{1}{A_{2}} S_{0} ; 0.11 \leq B \leq 0.14, \\
\frac{1}{A_{3}} S_{0} ; 0.21 \leq B \leq 0.28, \\
\frac{1}{A_{4}} S_{0} ; 0.37 \leq B \leq 0.83,
\end{array}\right.
$$

where $B=L h / H^{2}$ - the relation of the product of the distance between the diaphragm wall and the depth of laying the foundation of an existing building to the square of the depth of excavation.

$A \_i$ - the relation ratio $S_{0} / S \_t$, determined by the following formulas for $h=2.0 \mathrm{~m}$ and $B$ $\in[0.03 ; 0.07] \cup[0.11 ; 0.14] \cup[0.21 ; 0.28] \cup[0.37 ; 0.83]$

$$
\left\{\begin{array}{l}
A_{1}=-4.48 B^{2}-0.18 B+1.07 \\
A_{2}=59.69 B^{2}-17.35 B+2.35 \\
A_{3}=-43.75 B^{2}+19.4 B-0.87 \\
A_{4}=4.76 B^{2}-5.65 B+2.84
\end{array}\right.
$$




\section{Discussion}

Estimating the settlement of the building, taking into account the life of the building when assessing the impact of new construction in the framework of the work done, the following can be noted:

- When analyzing the results of building foundations, there is a significant difference between the maximum settlement taking into account the operating time $S \_t$ and the maximum settlement $S_{0}$ determined by the traditional method (figure 3 ),

- The research data must be continued to increase the interval of the parameter $B$ and to enable the transformation of a piecewise function into a continuous,

- Taking into account the soil hardening can significantly save on strengthening the structures of existing buildings, abandoning it in some cases and justifying it by calculations. In particular, this can be done from the obtained formulas (3), taking into account the conditions for their application.

\section{Conclusions}

As a result of the calculations performed, given the initial data, we can draw the following conclusions:

- The results of numerical calculations confirm the conclusion that the improvement of the strength characteristics of soils in the grounds of long-term buildings should be taken into account,

- This feature can be used in the construction of additional floors and reconstruction of a building with increasing loads on existing foundations, as well as in estimating the impact from new construction in order to reduce construction costs,

- The data of the conducted studies will contribute to the further development of the calculation methodology for assessing the impact of new construction.

This work was financially supported by Ministry of Science and Higher Education of the Russian Federation (\#NSh-3492.2018.8).

\section{References}

1. Yu.I. Dvorkin, Osn., fund. i mekh. gr. 4 23-24 (1982)

2. V.A. Zurnadzhi, M.P. Filatova, Usilenie osnovanij i fundamentov pri remonte zdanij (Strojizdat, Moscow, 1970)

3. P.A. Konovalov, Osnovaniya $i$ fundamenty rekonstruiruemyh zdanij (VNIINTPI, Moscow, 2000)

4. Yu. Kirichek, V. Konnik, D. Stan, Osadki zdanij pri uvelichenii nagruzok na fundamenty melkogo zalozheniya (CGE-2017, Kyiv, 2017)

5. I.V. Koroleva, Nesushchaya sposobnost' $i$ osadka osnovanij fundamentov s uchetom dlitel'nogo i nelinejnogo deformirovaniya gruntov ( $\mathrm{PhD}$ in Engineering sciences thesis, Kazan', 2011)

6. A.I. Polishchuk, Osnovy proektirovaniya i ustrojstva fundamentov rekonstruiruemyh zdanij (STT, Northehmpton, Tomsk, 2004)

7. E.A. Sorochan, YU.I. Dvorkin, Osn., fund. i mekh. gr. 2 8-9 (1976)

8. V.B. Shvec, V.I. Feklin, L.K. Ginzburg, Usilenie $i$ rekonstrukciya fundamentov (Strojizdat, Moscow, 1985) 